\title{
Folic acid level and preterm birth among Sudanese women
}

Manal E. Sharif ${ }^{1}$, Ahmed Mohamedain ${ }^{2,3}$, AbdelBagi A. Ahmed ${ }^{4}$, Abubakr M. Nasr ${ }^{2}$ and Ishag Adam² (D)

\begin{abstract}
Background: Preterm birth (PTB) is the major health problem world-wide; there are few published studies on PTB and folic acid.

Methods: The study was conducted to assess the serum level of folic acid in PTB. A case-control study was conducted at Saad Abualila maternity hospital (Khartoum, Sudan) during the period of March through December 2015. Women who delivered live singleton babies were dived in two groups; the cases were women who had PTB "delivery before completed 37weeks but after 24 weeks of pregnancy" and the controls were women who delivered at term (37-42 weeks). Medical and obstetrics history was gathered using questionnaire. Serum folic acid was measured.
\end{abstract}

Results: One hundred and twelve (56 in arm of the study) women were enrolled to the study. There was no significant difference between the cases and the controls in their age, parity, hemoglobin, body mass index, education and occupation. The median (interquartile) level of folic acid was significantly lower in the cases (PTB) than the level in the controls, 4.8(2.8-8.2) vs. 9.5(8.6-12.0) $\mathrm{ng} / \mathrm{ml}$. In binary regression, folic acid level was associated with lower risk of PTB $(\mathrm{OR}=0.64 ; 95 \%=0.53-0.77, P<0.001)$. There was a significant positive correlation between gestational age and folic acid level $(r=0.447, P<0.001)$.

Conclusion: Thus serum folic acid level was significantly lower in women with PTB. Folic acid level was associated with lower risk of PTB.

Keywords: Preterm birth, Folic acid, Pregnancy, Sudan

\section{Background}

Preterm birth (PTB) is defined by the World Health Organization as "as the delivery of the fetus before completed 37 weeks of gestation or 259 days from the first day of the last menstrual period"('World Health Organization. International statistical classification of diseases and related health problems. 10th ed. Geneva: [1]). PTB is a major health problem worldwide where it has been estimated that 14.9 million babies were born preterm, which estimates to $11.1 \%$ of all live births globally [2]. PTBs are the main cause of neonatal deaths and they are at a higher risk for adverse outcomes later in life e.g. cerebral palsy and learning difficulties [3]. There are two subtypes of PTB; either spontaneous (70\%) "spontaneous onset of labor with intact membranes

\footnotetext{
* Correspondence: Ishagadam@hotmail.com

${ }^{2}$ Faculty of Medicine, University of Khartoum, P.O Box 102, 11111 Khartoum, Sudan

Full list of author information is available at the end of the article
}

and preterm premature rupture of the membranes" or provider-indicated (iatrogenic, 30\%) PTB "induction of labor or caesarean birth prior to 37 weeks of gestation" $[4,5]$.

Investigating the predictors for PTB is of paramount for health planners and care givers. The research could yield a helpful data to guide/implement the preventive measures for PTB. Various clinical and biological factors have been shown to be associated with PTB in different settings. [5-8]. Folate/folic acid has been studied extensively for its association with adverse pregnancy outcomes such as PTB. However, the available literature on the relationship between folate/folic acid and PTB has been inconclusive. While, some studies have found that lower levels of folate during pregnancy associated with increases the risk of PTB [9-11], other studies have failed to show association between folic acid or folate concentrations and PTB [12-14]. PTB is a major health 
problem in Sudan $[7,8]$. The current study was conducted to assess the association between folic acid level and PTB.

\section{Methods}

A case - control study was conducted at Saad Abualila maternity hospital (Khartoum, Sudan) during the period of March through December 2015. Saad Abualila is a tertiary hospital affiliated to the Faculty of Medicine, University of Khartoum, Sudan.

After signing an informed consent, women presented labour and had singleton babies were approached to participate in the study. The cases were women who had PTB "delivery before completed 37weeks but after 24 weeks of pregnancy, (spontaneous onset of labour or following preterm premature rupture of membranes)". The controls were women who delivered a live born singleton baby at term (37-42 weeks). Women with intrauterine fetal death, major congenital malformation, and twins, diabetes, hypertension and antepartum haemorrhage were excluded from the cases and controls because of their known tendency to influence the risk of PTB.

From all women (cases and controls) medical and obstetrical history (age, parity, gestational age, and history of miscarriage) was gathered using a questionnaire which was filled by a trained medical officer. Gestational age was calculated from first day of the last menstrual and confirmed by ultrasound scan in the first half of pregnancy. The interpregnancy interval (IPI) was defined as the time between the woman's previous delivery, miscarriage and the first day of the last menstrual period for the index pregnancy. Body mass index (BMI) was calculated by dividing weight in $\mathrm{kg}$ by height in meters squared $\left(\mathrm{kg} / \mathrm{m}^{2}\right)$.

Then venous blood was collected from each woman and allowed to clot in plain tubes, and the serum was stored at $-20{ }^{\circ} \mathrm{C}$ until analysed for serum folate which was determined by immunofluorescent assay using IMMULITE kits according to the manufacturers' instructions (SIEMENS Healthcare, Los Angeles, CA, USA) that we have described in our previous work [15].

A total sample of 56 participants in each arm of the study was calculated to investigate the mean difference of the folic acid level. This sample size would provide over $80 \%$ power to detect a $5 \%$ difference at $\alpha=0.05$, with an assumption that complete data might not be available for $10 \%$ of participants [16].

\section{Statistics}

Data were entered in computer and SPSS for Windows (version 20) was used for data analyses. Continuous data were checked for normality using Shapiro-Wilk test. Data were expressed as proportions; mean (SD), median (interquartile). Mean, median (if the continuous data were not normally distributed) and proportions were compared between the cases and the controls by t-test, MannWhitney $U$ and Chi-square test, respectively. Binary regression model was built where preterm delivery was the dependent variable and age, parity, education, antennal care, interpregnancy interval, hemoglobin and folic acid level were the independent variables. Odd ratios and 95\% confidence interval were calculated. $P<0.05$ was considered statistically significant. Pearson correlation was performed between gestational age and folic acid level.

\section{Results}

One hundred and twelve (56 in arm of the study) women were enrolled to the study. The mean (SD) of their age, parity and BMI was 28.3(6.0) years, 2.4(2.3) and $26.3(4.2) \mathrm{kg} / \mathrm{m}^{2}$, respectively. Around one third (35.0, 31.3\%) of these women had history of miscarriage. The majority $(99.0,88.4 \%$ ) of the participants were housewives. The serum folic acid level was not normally distributed and its range from $0.9-23.0 \mathrm{ng} / \mathrm{ml}$, the mean and median were 8.1 and $8.6 \mathrm{ng} / \mathrm{ml}$, respectively.

There was no significant difference between the cases and the controls in their age, parity, hemoglobin, BMI, education and occupation, Table 1.

The median (interquartile) level of folic acid was significantly lower in the cases (PTB) than the level in the controls, $4.8(2.8-8.2)$ vs. $9.5(8.6-12.0) \mathrm{ng} / \mathrm{ml}$ (Fig. 1).

In binary regression, folic acid level was associated with lower risk of PTB $(\mathrm{OR}=0.64 ; 95 \%=0.53-0.77$, $P<0.001$, Table 2 . There was a significant positive correlation between gestational age and folic acid level $(r=0.447, P<0.001)$.

\section{Discussion}

The main finding of the current study was the significant lower level of serum folic acid in women with PTB and folic acid level was associated with lower risk of PTB. This goes with the previous studies where Chen et al., have reported that higher plasma folate concentrations were associated with a longer gestational age and associated with lower risk of PTB [9]. Likewise Furness et al., have shown that women who had a lower Red blood cells (RBCs) folate level in early (12-14 weeks) pregnancy were 5.4 times at higher risk to have PTB [11]. In a large clinical trial, it has recently been shown consumption of folic acid/ other micronutrient in the first trimester lead to a $41 \%-$ $45 \%$ risk reduction for PTB [17].

In contrast to our findings, it has recently been reported that supplemental folate intake was not significantly associated with the risk of PTB [12]. Interestingly, women who received folic acid supplementation more than 8 weeks before conception were at increased risk for PTB compared with women who received no folic acid supplementation preconception [12]. In a large 
Table 1 comparison of the variables between the cases and controls

\begin{tabular}{|c|c|c|c|}
\hline Variables & The cases $(n=56)$ & The controls $(n=56)$ & $P$ \\
\hline \multicolumn{4}{|l|}{ The mean (SD)of } \\
\hline Age, year & $28.3(6.2)$ & $28.3(5.9)$ & 0.996 \\
\hline Parity & $2.6(2.7)$ & $2.1(1.7)$ & 0.243 \\
\hline Body mass index, $\mathrm{kg} / \mathrm{m}^{2}$ & $26.2(4.3)$ & $26.4(4.0)$ & 0.825 \\
\hline Interpregnancy interval, month & 24.4(18.7) & $14.9(10.2)$ & 0.004 \\
\hline Hemoglobin, g/dl & $10.0(0.9)$ & $10.2(1.0)$ & 0.229 \\
\hline \multicolumn{4}{|l|}{ Number (percentage)of } \\
\hline Education < secondary level & $39(69.6)$ & $29(51.8)$ & 0.051 \\
\hline Housewives & $51(91.1)$ & $48(85.7)$ & 0.278 \\
\hline History of miscarriage & $15(26.8)$ & $20(35.7)$ & 0.208 \\
\hline Lack of antenatal care & $10(18.2)$ & $6(10.9)$ & 0.209 \\
\hline
\end{tabular}

longitudinal study (5075 women) Yamada and colleagues failed to detect a significant association between serum folate levels during the first trimester and the risk of PTB [13]. In the later study nineteen of the 20 women with folate deficiency had no PTD. Likewise a large previous study failed to show associations of plasma folate with PTB [14]. The recent met- analysis of randomized clinical trials (included 5332 women) concluded that folic acid supplementation during pregnancy did not prevent PTB [18].

Folate has an essential role in DNA methylation and synthesis [19]. Therefore low folate concentrations can lead to unfavorable cell division and subsequently poor placentation (Scholl \& Johnson, 2000). The exact mechanisms by which low folate levels are associated with PTB is not fully understood, perhaps through the homocysteine level $[9,10]$. It has been shown that the women with low/normal homocysteine levels were four times at a higher risk of PTB compared with those with elevated concentrations than those with [20]. Therefore it is

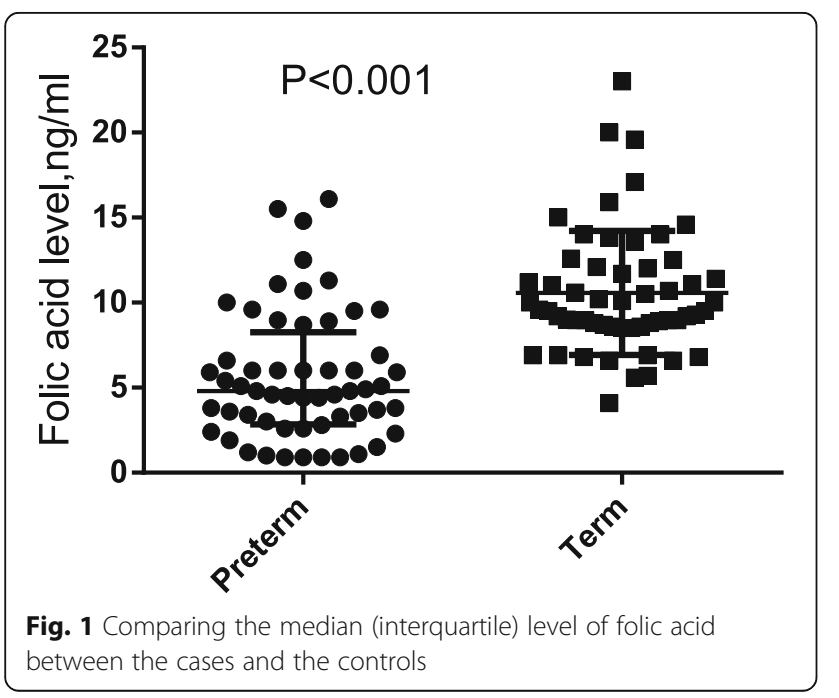

valuable to measure folate as well as its metabolites including homocysteine when investing folate and PTB. It is worth to be mentioned that, not only folate, or homocysteine level but also the role of genetics/mutations in pathway in the DNA repair, synthesis, methylation and its association with PTD has been observed [21, 22]. Several mutations in the methylene tetrahydrofolate reductase gene-which is responsible for the production of the active form of folate- have been shown to have an association with PTB [23, 24]. Several studies have shown that these SNPs result in an increased demand for folic acid [21, 22]. Thus these genetic factors/mutations have to be considered in the after coming research on folic acid and the associations with adverse pregnancy outcomes include PTB.

It is worth to be mentioned that in a recent Cochrane review where 17,771 women were included (in thirtyone trials) no conclusive evidence of benefit of folic acid supplementation during pregnancy on PTB was found [25]. We did not investigate cigarettes smoking in the current study. Perhaps smoking is not widely practiced among these women. Moreover, according to the Sudanese

Table $\mathbf{2}$ binary regression of the factors associated with preterm delivery

\begin{tabular}{llll}
\hline Variables & OR & $95 \% \mathrm{Cl}$ & $P$ \\
\hline Age, years & 1.03 & $0.94-1.13$ & 0.485 \\
Parity & 0.93 & $0.72-1.20$ & 0.589 \\
Education < secondary level & 1.26 & $0.68-2.31$ & 0.454 \\
Housewives & 0.78 & $0.29-2.11$ & 0.633 \\
History of miscarriage & 0.84 & $0.27-2.57$ & 0.768 \\
Lack of antennal care & 1.40 & $0.62-3.17$ & 0.415 \\
Body mass index, $\mathrm{k} / \mathrm{m}^{2}$ & 0.95 & $0.84-1.08$ & 0.503 \\
Hemoglobin level, g/dl & 0.78 & $0.45-1.34$ & 0.373 \\
Interpregnancy interval, months & 1.06 & $1.00-1.12$ & 0.049 \\
Folic acid level & 0.64 & $0.53-0.77$ & $<0.001$ \\
\hline
\end{tabular}


tradition, it is still difficult to investigate cigarettes smoking among females. Actually we have feared to lose the women's co-operation or to be answered wrongly if such point was included in the questionnaire. Missing the information on smoking should be mentioned as limitation of the current study. A correlation between smoking and folate level has been reported [11, 14]. Other limitations of the study were; other confounding variables (infections) that were not addressed in the questionnaires given to the pregnant mothers, it was a small sample size (especially in the control group) single center study.

\section{Conclusion}

The current showed that the serum folic acid level was significantly lower in women with PTB. Folic acid level was associated with lower risk of PTB.

\section{Abbreviations}

BMI: body mass index; Cl: confidence interval; OR: odd ratio; PTB: preterm birth; SD: standard devotion

\section{Acknowledgements}

The authors wish to express their sincere gratitude to Mr. Abdulla Hafaz Alla for technical assistance.

\section{Availability of data and materials}

Please contact author for data requests.

\section{Funding}

None received

\section{Authors' contributions}

MES and IA design the study, AM and AAA conducted the clinical work. AM, MES conducted the laboratory work. IA and AMN conducted analyses. All the authors approved the manuscript.

\section{Ethics approval and consent to participate}

The study was approved by the Department of Obstetrics, Medical College, University of Khartoum Institutional Review Board.

\section{Consent for publication}

Not applicable

\section{Competing interests}

The authors declare that they have no competing interests.

\section{Publisher's Note}

Springer Nature remains neutral with regard to jurisdictional claims in published maps and institutional affiliations.

\section{Author details}

'Faculty of Medicine, Al-Neelain University, P.O Box 12702, 11111 Khartoum Sudan. ${ }^{2}$ Faculty of Medicine, University of Khartoum, P.O Box 102, 11111 Khartoum, Sudan. ${ }^{3}$ Department of Biomedical Sciences, King Faisal University, Alhasa, Kingdom of Saudi Arabia. ${ }^{4}$ Department of Obstetrics and Gynecology, College of Medicine, King Khalid University, Abha, Kingdom of Saudi Arabia.

\section{Received: 15 June 2017 Accepted: 24 October 2017}

Published online: 01 December 2017

\section{References}

1. World Health Organization. International statistical classifica- tion of diseases and related health problems. 10th ed. Geneva: World Health Organization; 1992 1993. 2:1993.

2. Blencowe $H$, Cousens $S$, Oestergaard MZ, Chou D, Moller A-B, Narwal R, et al. National, regional, and worldwide estimates of preterm birth rates in the year 2010 with time trends since 1990 for selected countries: a systematic analysis and implications. Lancet (London, England). 2012;379:2162-72.

3. Torchin H, Ancel P-Y, Jarreau P-H, Goffinet F. Épidémiologie de la prématurité : prévalence, évolution, devenir des enfants. J. Gynécologie Obs. Biol Reprod. 201544:723-31.

4. Goldenberg RL, Culhane JF, lams JD, Romero R. Epidemiology and causes of preterm birth. Lancet (London, England). 2008;371:75-84.

5. Blencowe H, Cousens S, Chou D, Oestergaard M, Say L, Moller A-B, et al. Born too soon: the global epidemiology of 15 million preterm births. Reprod Health. 2013;10:S2.

6. Hughes K, Sim S, Roman A, Michalak K, Kane S, Sheehan P. Outcomes and predictive tests from a dedicated specialist clinic for women at high risk of preterm labour: a ten year audit. Aust New Zeal J Obstet Gynaecol. 2017;57(4):405-11.

7. Adam I, Ismail MH, Nasr AM, Prins MH, Smits LJM. Low birth weight, preterm birth and short interpregnancy interval in Sudan. J Matern Fetal Neonatal Med. 2009;22:1068-71.

8. Alhaj AM, Radi E A, Adam I. Epidemiology of preterm birth in Omdurman maternity hospital, Sudan. J Matern Fetal Neonatal med. [internet]. 2010;23: 131-134. Available from: http://www.ncbi.nlm.nih.gov/pubmed/19565427

9. Chen L-W, Lim AL, Colega M, Tint M-T, Aris IM, Tan CS, et al. Maternal folate status, but not that of vitamins B-12 or B-6, is associated with gestational age and preterm birth risk in a multiethnic Asian population. J Nutr. [Internet]. 2015 [cited 2017 May 14];145:113-120. Available from: http://jn. nutrition.org/cgi/doi/10.3945/jn.114.196352

10. Bergen NE, Jaddoe WW V, Timmermans S, Hofman A, Lindemans J, Russcher $\mathrm{H}$, et al. Homocysteine and folate concentrations in early pregnancy and the risk of adverse pregnancy outcomes: the Generation R Study. BJOG [Internet]. 2012 [cited 2017 May 14];1 19:739-751. Available from: http://doi. wiley.com/10.1111/j.1471-0528.2012.03321.x

11. Furness DLF, Yasin N, Dekker GA, Thompson SD, Roberts CT. Maternal red blood cell folate concentration at 10-12 weeks gestation and pregnancy outcome. J Matern Fetal Neonatal Med. [Internet]. 2012 [cited 2017 May 14]; 25:1423-1427. Available from: http://www.tandfonline.com/doi/full/10.3109/ 14767058.2011 .636463

12. Sengpiel V, Bacelis J, Myhre R, Myking S, Devold Pay AS, Haugen M, et al. Folic acid supplementation, dietary folate intake during pregnancy and risk for spontaneous preterm delivery: a prospective observational cohort study. BMC Pregnancy Childbirth [Internet]. 2014 [cited 2017 may 14];14:375. Available from: http://www.ncbi.nlm.nih.gov/pubmed/25361626.

13. Yamada T, Morikawa M, Yamada T, Kishi R, Sengoku K, Endo T, et al. Firsttrimester serum folate levels and subsequent risk of abortion and preterm birth among Japanese women with singleton pregnancies. Arch Gynecol Obstet. [Internet]. 2013 [cited 2017 May 14];287:9-14. Available from: http:// link.springer.com/10.1007/s00404-012-2501-5

14. Nilsen RM, Vollset SE, Monsen ALB, Ulvik A, Haugen M, Meltzer HM, et al. Infant birth size is not associated with maternal intake and status of folate during the second trimester in Norwegian pregnant women. J Nutr [Internet]. 2010 [cited 2017 May 14];140:572-579. Available from: http://jn. nutrition.org/cgi/doi/10.3945/jn.109.118158

15. Abdelrahim II, Adam GK, Mohmmed AA, Salih MM, Ali NI, Elbashier MI, et al. Anaemia, folate and vitamin B12 deficiency among pregnant women in an area of unstable malaria transmission in eastern Sudan. Trans R Soc Trop Med Hyg. 2009:103:493-6.

16. Charan J, Biswas T. How to calculate sample size for different study designs in medical research? Indian J Psychol Med. [Internet]. 2013 [cited 2017 May 6];35: 121-126. Available from: http://www.ijpm.info/text.asp?2013/35/2/121/116232

17. Li Z, Mei Z, Zhang L, Li H, Zhang Y, Li N, et al. Effects of Prenatal Micronutrients Supplementation on Spontaneous Preterm Birth: Double-Blind Randomized Controlled Trial in China. Am J Epidemiol. [lnternet]. 2017 [cited 2017 May 19]; Available from: http://www.ncbi.nlm.nih.gov/pubmed/28472219.

18. Saccone G, Berghella V. Folic acid supplementation in pregnancy to prevent preterm birth: a systematic review and meta-analysis of randomized controlled trials. Eur J Obstet Gynecol Reprod Biol. [Internet]. 2016 [cited 2017 may 19];199:76-81. Available from: http://www.ncbi.nlm.nih.gov/ pubmed/26901401.

19. Crider KS, Yang TP, Berry RJ, Bailey LB. Folate and DNA methylation: a review of molecular mechanisms and the evidence for folate's role. Adv Nutr. [Internet]. 2012 [cited 2017 May 14];3:21-38. Available from: http:// advances.nutrition.org/cgi/doi/10.3945/an.111.000992

20. Ronnenberg AG, Goldman MB, Chen D, Aitken IW, Willett WC, Selhub J, et al. Preconception folate and vitamin B(6) status and clinical spontaneous 
abortion in Chinese women. Obstet Gynecol. [nternet]. 2002 [cited 2017 may 18]; 100:107-113. Available from: http://www.ncbi.nlm.nih.gov/pubmed/12100811.

21. Nan Y, Li H. MTHFR genetic polymorphism increases the risk of preterm delivery. Int J Clin Exp Pathol. [Internet]. 2015 [cited 2017 May 18];8:7397-7402. Available from: http://www.ncbi.nlm.nih.gov/pubmed/26261642

22. Wang BJ, Liu MJ, Wang Y, Dai JR, Tao JY, Wang SN, et al. Association between SNPs in genes involved in folate metabolism and preterm birth risk. Genet Mol Res. [nternet]. 2015 [cited 2017 May 18];14:850-859. Available from: http://www. funpecrp.com.br/gmr/year2015/vol14-1/pdf/gmr4222.pdf

23. Zeisel SH. Importance of methyl donors during reproduction. Am J Clin Nutr. [Internet]. 2009 [cited 2017 May 18];89:673S-677S. Available from: http://www.ajcn.org/cgi/doi/10.3945/ajcn.2008.26811D

24. Zhu Q, Chen Y, Dai J, Wang B, Liu M, Wang Y, et al.

Methylenetetrahydrofolate reductase polymorphisms at 3'-untranslated region are associated with susceptibility to preterm birth. Transl Pediatr [Internet]. 2015 [cited 2017 may 19];4:57-62. Available from: http://www. ncbi.nlm.nih.gov/pubmed/26835361.

25. Lassi ZS, Salam RA, Haider BA, Bhutta ZA. Folic acid supplementation during pregnancy for maternal health and pregnancy outcomes. In: Bhutta ZA, editor. Cochrane database Syst Rev. [internet]. Chichester, UK: John Wiley \& Sons, Itd; 2013 [cited 2017 may 14]. p. CD006896. Available from: http:// www.ncbi.nlm.nih.gov/pubmed/23543547

\section{Submit your next manuscript to BioMed Central} and we will help you at every step:

- We accept pre-submission inquiries

- Our selector tool helps you to find the most relevant journal

- We provide round the clock customer support

- Convenient online submission

- Thorough peer review

- Inclusion in PubMed and all major indexing services

- Maximum visibility for your research

Submit your manuscript at www.biomedcentral.com/submit 